\section{Prediction of dominance in social groups of the electric fish, Gymnotus carapo}

\author{
G. W. MAX WESTBY and HILARY O. BOX \\ The University of Reading, Whitknights, Reading, England
}

Eight adult Gymnotus carapo were used in an experiment designed to examine electrical and other behavioral interactions within 22 different pairings of animals. High scores on aggressive behavior were inversely related to the time spent in electrical silence. Approach and threat movement scores were positively correlated. Of particular interest in this study was the perfect positive correlation between electrical pulse frequency and subsequent display of threat movements in social encounters. In general the results confirmed a suggestion that dominance in this type of social grouping can be reliably predicted from the electrical characteristics of the interacting individuals.

Most recent work on electric fish has been centered on the anatomy and physiology of the electric organs (Bennett, 1961; Bennett \& Grundfest, 1959; Grundfest, 1957), the electroreceptor systems (Bennett, 1968), and the control of electric-organ discharge by medullary pacemaker systems (Bennett et al, 1967; Enger \& Szabo, 1965).

Earlier work (Lissman, 1958; Lissman \& Machin, 1958; Machin \& Lissman, 1960) demonstrated the orientation and discrimination abilities of the weakly electric gymnotids and mormyrids based upon an electric sense which involved detection of changes in the electric field surrounding the fish.

Apart from the discrimination function of the electrical transmission-reception system of these animals, there has been some speculation over its possible importance in social communication. Möhres (1957) found that the introduction of a mormyrid into a tank already occupied by a member of the same species led to a simultaneous increase in the discharge frequency of both fish. Möhres proposed that the discharge of the intruder released the fighting behavior of the resident and that electrical discharge has a territorial function similar to that of bird song. Lissman (1958) noted that mechanical disturbance of one of two mormyrids in a partitioned tank led to a frequency increase in both fish, whereas the same disturbance in an empty compartment had no effect on either. Furthermore, Szabo, in Lissman (1961) reported instances in which increases in pulse frequency by one fish led to the cessation of discharge in another. It is this cessation of discharge which is of particular interest and is further discussed in Szabo \& Suckling (1964).

More recently a report of several years' work ascribes a possible social function to the electrical behavior of several species of electric fish (Bullock, 1969). For example,
Bullock and his coworkers found that an increase in the low-voltage electrical discharge rate of Electrophorus was very effective in arousing and attracting resting electric eels over a distance of several meters. High discharge rates are normally produced while feeding or reacting to a variety of stimuli.

A South American gymnotid, Gymnotus carapo, was used in the present study. This species is characterized by a low resting discharge frequency of approximately $60 \mathrm{~Hz}$ together with a high standard deviation of interval length. It also responds to many types of stimuli by large increases in frequency [Group A of Bullock's (1969) classification] .

Studies of the social behavior of gymnotus are rare, Box \& Westby (1970) studied the behavior of four different two-member groups in an experimental situation and related certain aspects of electrical activity to components of agonistic behavior. This work and the study to be presented here complement a recent unpublished thesis (Cleworth, 1969), in which independent experiments also investigated the role of electrical discharge in the social behavior of Gymnotus carapo.

\section{METHOD}

The experimental situation and maintenance conditions were exactly the same as reported in our previous paper

In this case, eight adult Gymnotus carapo, of unknown age and sex, were used. Immediately prior to the social experiment, each animal was given a series of habituation trials. During these trials each animal was observed individually in the experimental tank for a period of $10 \mathrm{~min}$ per day for 4 days. Frequency readings were taken every $60 \mathrm{sec}$, and activity was continuously recorded on an "open-field" type grid which divided the bottom of the experimental tank into eight equal areas. From these observations a (Box \& Westby, 1970). mean pulse frequency and an activity score was assigned to each animal.

In the social experiment, interactions between pairs of animals were observed. We intended to use all the possible 28 pairings. However, S 4 became very aggressive during its first pairing with $\mathrm{S} 7$, and Animal 7 died before the end of the experiment. Consequently, S4 was removed from this study, but the results for the interactions involving $\mathrm{S} 7$ were retained, as they did not markedly affect

Table 1

Total Scores for Each $S$ in Each Interaction

Electrical Behavior

Total Number

Threat Time of

$\begin{array}{rrrr}\text { Appro- } & \begin{array}{c}\text { Mhreat } \\ \text { Group }\end{array} \text { "Off" } & \text { of } \\ \text { "Turn } \\ \text { aches ments } & \text { (Sec) } & \text { Offs" }\end{array}$

$\begin{array}{llllll}1+3 & 1 & 2 & 16 & 10 & 12\end{array}$

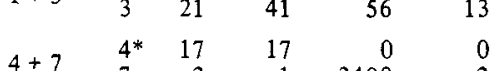

$\begin{array}{rrrrrr}4+7 & 7 & 2 & 1 & 3400 & 2\end{array}$

$\begin{array}{rrrrrr}5+8 & 5 & 6 & 5 & 1940 & 49\end{array}$

$\begin{array}{rrrrrr}1+2 & 1 & 4 & 3 & 44 & 13\end{array}$

$\begin{array}{llllll}1+2 & 2 & 19 & 28 & 7\end{array}$

$\begin{array}{rrrrrr}3+5 & 3 & 11 & 8 & 0 & 0\end{array}$

$\begin{array}{rrrrrr}7+8 & 7 & 5 & 2 & 3405 & 5\end{array}$

$\begin{array}{llllll}1+6 & 1 & 17 & 3 & 481 & 19\end{array}$

$2+3 \quad 2 \quad 34 \quad 33 \quad 10 \quad 3$

$\begin{array}{rrrrrr} & 7 & 1 & 0 & \\ 1 & 1 & 10 & 4 & 36 & 11\end{array}$

$\begin{array}{rrrrrr}1+8 & 1 & 10 & 4 & 36 & 11 \\ \cdot & 8 & 11 & 4 & 0 & 0\end{array}$

$\begin{array}{rrrrrr}3+6 & 3 & 12 & 3 & 171 & 1 \\ & 6 & 18 & 8 & 4 & 3\end{array}$

$\begin{array}{llllll}5+7 & 5 & 4 & 2 & 203 & 15\end{array}$

$1358 \quad 11$

$\begin{array}{llllll}2+8 & 2 & 73 & 16 & 21 & 7\end{array}$

$\begin{array}{llllll}6+7 & 6 & 17 & 1 & 0 & 0\end{array}$

$\begin{array}{rrrrrr}2+5 & 2 & 34 & 8 & 0 & 0\end{array}$

$\begin{array}{rrrrr}5 & 5 & 1 & 5 & 2\end{array}$

$\begin{array}{rrrrrr}1+7 & 1 & 15 & 2 & 10 & 1 \\ & 7 & 2 & 0 & 2605 & 9\end{array}$

$\begin{array}{llllll}3+8 & 3 & 14 & 0 & 4 & 2 \\ & 8 & 21 & 0 & 4 & 3\end{array}$

$\begin{array}{rrrrrr}5+6 & 5 & 3 & 0 & 44 & 7\end{array}$

$\begin{array}{rrrrrr}7+2 & 7 & 7 & 0 & 2604 & 9\end{array}$

$\begin{array}{llllll}6+8 & 6 & 34 & 1 & 52 & 17\end{array}$

$\begin{array}{llllll}6+8 & 8 & 22 & 1 & 48 & 12\end{array}$

$\begin{array}{rrrrrr}1+5 & 1 & 15 & 1 & 2 & 1 \\ & 5 & 3 & 0 & 0 & 0\end{array}$

$3+7 \quad 3 * *$

\begin{tabular}{rrrrrr}
$2+6$ & 2 & 17 & 5 & 0 & 0 \\
& 6 & 5 & 3 & 19 & 6 \\
\hline
\end{tabular}

* $S 4$ was removed after this trial.

** 77 died before thes trial could be run. 
Table 2

Mean Scores for Measures Taken During the Habituation Triats and During the Social Interactions

\begin{tabular}{|c|c|c|c|c|c|c|c|c|}
\hline \multirow{2}{*}{$\begin{array}{c}\text { Habitu- } \\
\text { ation } \\
\text { Trials }\end{array}$} & Category & S1 & S2 & S3* & S5 & S6 & $\$ 7^{*}$ & $\$ 8$ \\
\hline & $\begin{array}{l}\text { Mean Pulse Frequency } \\
\text { Mean Activity Score }\end{array}$ & $\begin{array}{c}67.12 \\
47.5 \\
\end{array}$ & $\begin{array}{l}71.81 \\
42.88 \\
\end{array}$ & $\begin{array}{l}67.84 \\
33.13 \\
\end{array}$ & $\begin{array}{c}47.14 \\
7.75 \\
\end{array}$ & $\begin{array}{l}67.83 \\
30.63 \\
\end{array}$ & $\begin{array}{l}60.55 \\
30.38 \\
\end{array}$ & $\begin{array}{l}65.68 \\
54.25 \\
\end{array}$ \\
\hline \multirow{4}{*}{$\begin{array}{l}\text { Experi- } \\
\text { mental } \\
\text { Trials }\end{array}$} & $\begin{array}{l}\text { Mean Number } \\
\text { of Approaches }\end{array}$ & 10.5 & 33.3 & 18.4 & 3.8 & 25.3 & 3.8 & 20.8 \\
\hline & $\begin{array}{l}\text { Mean Number } \\
\text { of Threats }\end{array}$ & 4.7 & 15.0 & 10.6 & 0.6 & 7.0 & 0.8 & 3.7 \\
\hline & $\begin{array}{l}\text { Mean Number } \\
\text { of "Turn Offs" }\end{array}$ & 9.5 & 2.0 & 3.2 & 18.8 & 5.2 & 9.0 & 4.6 \\
\hline & $\begin{array}{l}\text { Mean Time "Turned } \\
\text { Off" (Seconds) }\end{array}$ & 97.2 & 6.3 & 46.2 & 648.5 & 23.5 & 3190.4 & 18.7 \\
\hline
\end{tabular}

* Mean scores represent five trials only for $S 3$ and $S 7$.

the general trends.

Each $S$ experienced a single 1-h interaction with every other $S$ except for the above-mentioned Ss 4 and 7. The remaining 21 th trials were run at the rate of two per day for 11 days. The trials were carried out in a pseudorandom order such that no animal was tested twice on the same day.

The behavior during the social interactions was recorded in shorthand by one $E$ while the other recorded the electrical activity of the animals. Both the number and duration of occurrences of electrical silence or "turn-off" were recorded for each animal. The behavior was condensed into the two main categories of agonistic behavior described previously (Box \& Westby, 1970). These were approach, which was only scored when it resulted in body contact, and threat movements, which comprised head butting, chasing, and biting.

\section{DISCUSSION}

The data obtained in the experimental trials is summarized in Table 1. For each grouping the total number of approaches and threat movements is given, together with the total number of "turn-offs" and the total time spent "turned-off" for each $S$. The mean values over the whole experiment are given in the lower half of Table 2. The upper half of Table 2 gives the mean scores for each $S$ for frequency and activity obtained over the 4 days of habituation trials.

Our first interest was to test hypotheses generated by our first experiment (Box \& Westby, 1970), in which only four animals were used. These were that high scores on aggressive behavior (approaches and threat movements) were inversely related to the time spent electrically silent, and that the frequency of pulse emission measured prior to the experiment was directly related to the extent of aggressive behavior displayed in social interactions.

The rank correlation coefficients between the six measures taken in this study are presented in Table 3, together with their significance levels. First, as expected, approach and threat movement scores are positively correlated. Confirming our earlier results, approach and time spent "turned-off" are highly negatively correlated $(\mathrm{p}<.01)$; similarly threat movements and time spent tumed off are negatively correlated $(p<.05)$. The number of electrical turn-offs was positively correlated with time spent turned-off and yielded similar correlations to the latter throughout the other comparisons.

Of particular interest in this study is the perfect positive correlation between pulse frequency and subsequent display of threat movements in social encounters. Correlations between frequency and approach and measures of electrical silence all yielded significant values in the expected direction.

These results thus confirm the tentative suggestion that dominance in this type of social grouping can be reliably predicted

Table 3

Spearman Rank Correlation Coefficients Between the Measures Taken for All Seven Ss

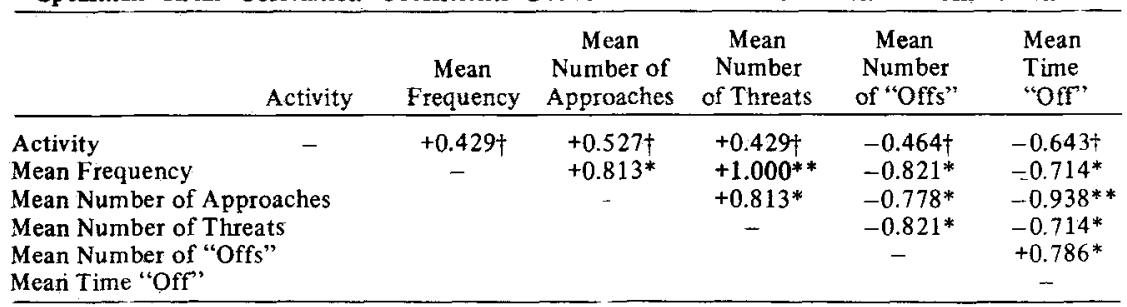

tnot significant; ${ }^{*} p \leqslant 0.05 ;{ }^{*} p \leqslant 0.01$ from the electrical characteristics of the interacting fish (Box \& Westby, 1970).

Work on the relationship between the frequency of pulse emission and arousal in electric fish (Dewsbury, 1966) and the observations of many others (e.g., Bullock, 1969; Lissman, 1958) indicate the many factors affecting the frequency of a given species of electric fish. Apart from the individual differences that exist, the general level of activity appears to affect the frequency most. It might thus be argued that the more aggressive, higher-frequency animals in this study were also the most active and their frequency differences were simply reflecting activity differences. Correlation coefficients for activity and the other measures in Table 3 lend little support to this explanation. Activity and frequency are positively correlated, but not significantly. Similarly, none of the other correlations with activity are significant.

This raises various questions, in particular the possibility of individual recognition on the basis of electrical characteristics. More work along these lines is at present in progress in this laboratory.

An almost linear hierarchy of aggressive and "turning-off" behavior is evident from the results in Table 1, supporting our previous findings. The behavior of a given animal varies considerably depending on the animal it is paired with.

An interesting fact emerging from Table 1 is the dramatic decline in scores for threat movements over trials. During the last eight or nine trials, very little of the aggressive behavior falling into the threat movement category is displayed. This is important since it indicates that as a result of social interactions with various individuals, an animal's subsequent behavior when faced with a stranger is considerably modified. It is significant that the approach scores are not affected in this way, indicating that perhaps something is learned about the relative effectiveness of these two intensities of aggressive behavior. $S 2$, the most dominant animal, displayed this change in behavior over days particularly well. This reduction in intensity is almost certainly related to a similar type of fall off in intensity, which we have observed within trials.

The present study, then, has demonstrated a strong inverse relationship between electrical "turning-off" and aggressive behavior in these animals. It is, therefore, tempting to suggest that "turning-off," which invariably immediately follows an aggressive contact (usually head butting) by the other member of the group, serves a signaling function. Previous workers (Box \& Westby, 
1970: (leworth. 1969) have suggested that "turning-ofl" may serve as a submissive signal. Certainly incidental observations confirm that the extent of aggression shown is greatly reduced when the opponent is electrically silent. We now feel that this work, in conjunction with our previous paper, in which stable groups were established, provides strong evidence for social communication in these animals via an electrical channel.

\section{REIERINCLS}

BENNETT, M. V. L. Modes of operation of electric organs. Annals of the New York Academy of Sciences, 1961, 94, 458-509.

BENNETT, M. V. L. Neural control of electric organs. In $\mathrm{D}$. Ingle (Ed.), The central nervous system and fish behavior. Chicago and London: University of Chicago Press, 1968.

BENNETT, M. V. L.. \& GRUNDFEST, $H$. Electrophysiology of the electric organ in Gymnotus carapo. Journal of General Physiology, 1959, 42, 1067-1104.

BENNETT, M. V. L., PAPPAS, G. D., GIMENEZ, M., \& NAKAJIMA, Y. Physiology and ultrastructure of electrotonic junctions. IV. Medullary electromotor nuclei in gymnotid fish. Journal of Neurophy siology, 1967, 30, 236-300.

BOX, H. O., \& WESTBY, G. W. M. Behavior of electric fish (Gymnotus carapo) in a group membership experiment. Psychonomic Science, 1970, 21, 27-28.

BULLOCK, T. H. Species differences in effect of electroreceptor input on electric organ pacemakers and other aspects of behavior in electric fish. Brain Behavior \& Evolution,
$1969,2,85-118$

CLI:WORTH, P. A. The role of electrical discharges in the non-reproductive social behavior of Gymnotus carapc. Unpublished PhD thesis, University of California at Los Angeles.

DFWSBURY, D. A. Stimulus-produced changes in the discharge rate of an electric fish and their relation to arousal. Psychological Record, 1966, 16, 495-504.

ENGER, P. S., \& SZABO, T. Activity of central neurons involved in electroreccption in some weakly electric fish (Gymnotidae). Journal of Neurophysiology, 1965, 28, 800-818.

GRUNDFEST, H. The mechanism of electric discharge in relation to general and comparative electrophysiology. Progress in Biophysics, 1957, 7, 1-86.

LISSMAN, H. W. On the function and evolution of electric organs in fish. Journal of Experimental Biology, 1958, 35, 156-191.

LISSMAN, H. W. Ecological studies on gymnotids. In C. Chagas and A. Paes de Corvallo (Eds.), Bioelectrogenesis. Amsterdam: Elsevier, 1961, Pp. 215-223.

LISSMAN, H. W., \& MACHIN, K. E. The mechanisms of object location in Gymnarchus niloticus and similar fish. Journal of Experimental Biology, 1958, 35, 451-486.

MACHIN, K. E., \& LISSMAN, H. W. The mode of operation of the electric receptors in Gymnarchus. Joumal of Experimental Bjology, 1960, 37, 801-811.

MOHRES, F. P. Elektrische Entladungen im Dienste der Revierabsrenzung bei Fischen. Naturwissenschaften, 1957, 44, 431-432.

SZABO, T., \& SUCKLING, E. E. L'arrêt occasional de la décharge electrique continue du Gymnarchus est-il une réaction naturelle? Naturwissenschaften, $1964,51,92-94$

\section{Changes in preference for cage environments following habituation and shock in the Mongolian gerbil*}

\author{
HARVEY J. GINSBURG and WILLIAM G. BRAUD \\ University of Houston, Houston, Tex. 77004
}

Twelve Mongolian gerbils were given daily tests of their preference for their own familiar vs other novel litter environments. The gerbils showed a striking preference for the home environment which gradually declined over 6 days of testing. The home litter preference was reinstated following aversive stimulation. The data are discussed in terms of habituation, dishabituation, and fear. Some incidental observations on depth perception in this species are also reported.

Preliminary to a laboratory investigation of intraspecific aggression in the Mongolian gerbil (Meriones unguiculatus), 1 it was decided to ascertain whether gerbils would recognize and prefer their own litter environment to others'. If a definite preference were indicated, would it decrease or "habituate" upon repeated

*We are indebted to Dr. Gordon G. Gallup for his comments and suggestions.
90-120 days old at the time of testing and were all experimentally naive. The litters were housed separately in clear plastic compartments, $15 \times 11 \times 8$ in., with $1 / 4$-in. hardware cloth tops. Wood shavings covered the compartment bottoms. Ad lib food and water conditions were maintained throughout the experiment.

\section{APPARATUS}

A preference apparatus and a shock-administration apparatus were employed. The three plastic housing compartments described above served as the bases of the preference apparatus. Each litter compartment was fitted with a cover made of 1/4-in. hardware cloth. Three platforms of size equal to that of the compartment covers were then constructed out of the same material. The platforms were separately suspended by pulley systems $1 / 8$ in. above each covered litter compartment. In order to ensure that the platforms remained stationary above their compartments, small strips of latex rubber were employed to attach the corners of each platform to the corners of each associated cover. The platforms and compartment covers were connected to relays in such a manner that any pressure exerted on a given platform by the weight of an $S$ would complete a circuit that activated one of three electric timers corresponding to the litter above which the $S$ was situated. The amount of time $S$ spent above each litter environment was thus automatically accumulated.

The shock-administration apparatus was a commercial operant-conditioning chamber (Lehigh Valley Model 1578) with stainless steel grid bars.

\section{PROCEDURE}

The three litters were housed in their respective compartments for 3 days prior to testing. The tails of the Ss were marked so that individuals could be easily recognized and individual preference records maintained.

All Ss were given daily litter-preference tests on Days 4-11. A test consisted of placing an individual gerbil upon the platform of the leftmost compartment and starting a 10 -min trial timer. The gerbil could then move freely from platform to platform (which were spaced about $1 / 8$ in. apart). Only very rarely did a gerbil leave the platforms themselves, but rather spent its 10 -min session moving from platform to platform, sniffing the compartments and the perimeter of the platforms. At the time of testing, each compartment contained three of the four original inhabitants, two of the remainder being placed in individual cages awaiting their test trials, and the final $S$ being placed on the platforms. To avoid any spatial bias, the positions of the litter compartments beneath the platforms were 